\title{
ENVANTER ROTALAMA PROBLEMLERİ İÇİN YENİ ARAŞTIRMA ALANLARI
}

\author{
Ömer Utku KAHRAMAN, Erdal AYDEMIR*
}

Süleyman Demirel Üniversitesi, Mühendislik Fakültesi, Endüstri Mühendisliği Bölümü, Isparta, Türkiye

\begin{tabular}{ll}
\hline Anahtar Kelimeler & Özet \\
\hline Envanter Rotalama, & Envanter rotalama problemi, envanter yönetimi ve araç rotalama probleminin bir \\
Bilimsel Yazın Araştırması, & arada çözümü ile tanımlanır. Araç rotalama problemi ile dağıtım planlaması \\
Araç Rotalama, & öncesinde kısıtlar altında envanter yönetimi süreci ile dağıtım miktarları belirlenir. \\
Yeni Araştırma Alanları & Araç rotalama probleminde genellikle toplam alınan yol minimizasyonu ele \\
& alınırken, envanter rotalama probleminde müşterilerin envanter seviyelerinin de \\
& minimizasyonu amaçlanır. Problemin gelişim süreci de dikkate alınarak, bu \\
& çalışmada envanter rotalama problem için bilimsel yazın taraması detaylıca \\
& yapılmış ve yeni araştırma alanları endüstriyel katkılar sağlaması bakımından \\
& önerilmiştir.
\end{tabular}

\section{NEW RESEARCH DIRECTIONS TO INVENTORY ROUTING PROBLEMS}

\begin{tabular}{ll}
\hline Keywords & Abstract \\
\hline $\begin{array}{l}\text { Inventory Routing } \\
\text { Literature Review }\end{array}$ & $\begin{array}{l}\text { Inventory routing problem is combined of the inventory management and vehicle } \\
\text { Vehicle Routing }\end{array}$ \\
$\begin{array}{l}\text { New Research Directions } \\
\text { and distribution amounts are determined under constraints before distribution } \\
\text { planning. In the case of vehicle routing problem, it is generally minimizing the total } \\
\text { destination, inventory routing problem minimizing customers inventory levels. In } \\
\text { this study, a detailed scientific literature review is presented and then some new } \\
\text { research fields are proposed to researchers. }\end{array}$
\end{tabular}

\begin{abstract}
Alıntı / Cite
Kahraman, Ö. U., Aydemir, E. (2017). New Research Directions to Inventory Routing Problems, Journal of Engineering Sciences and Design, 5(1), 331-335.
\end{abstract}

\section{Giriş}

Giderek karmaşıklaşan endüstriyel ortamlar, yeni ve farklı ihtiyaçları ve problemleri ortaya çıkarmaktadır. Bilimsel yazında yapılan araştırmalar ise, bu yeni ihtiyaçları karşılamayı ve problemlere çözümler üretmeyi amaçlamaktadır. Bu çalışmanın da temel konusu olan, taşıma ve dağıtım problemleri içerisinde yer alan Envanter Rotalama Problemi (En-RP) de bu tür gelişmeyle ortaya çıkmış bir problem türüdür.

Belirli noktalar arasında, belirlenen taşıma yöntemleri kullanılarak yapılacak taşıma faaliyetlerinin hangi dağıtım noktalarından geçilerek gerçekleştirileceği kararı tedarik zinciri yönetiminde önemli bir karar problemidir. Müşteri taleplerinin tam karşılanması; en uygun maliyetli ve minimum zamanl teslimatların yapılması üretim ve dağıtım problemlerinin eş zamanlı yürütülmesiyle elde edilir. Araç rotalama problemleri (ARP) de üretim ve dağıtım problemlerinin entegre olarak ele alındığı bir problem türüdür. Merkez seçilen bir depodan coğrafi olarak dağılmış müşterilere veya talep noktalarına yapılan dağıtım ve rotalamanın, var olan araç veya araç filosunun kat ettiği toplam güzergâhı en küçükleyecek şekilde elde edilmesini ARP olarak tanımlanabilir (Kesen, 2012). Dağıtım problemlerinin çıkış noktası sayılan ARP'nin genel yapısında, ilk seçilen nokta depo olmak üzere $\mathrm{n}$ şehir ve $\mathrm{m}$ adet araç bulunmaktadır (Eryavuz ve Gencer, 2001).

Dağıtım problemleri ise; müşterilerden gelebilecek talep miktarlarını tahminleyerek, ürün veya malzemelerin depolardan dağıtım kanallarına ataması kararının verildiği problemler olarak ele alınabilmektedir. Dağıtım problemleri yapısında çok konumlu envanter rotalama ve dağıtım planlamasını barındırmaktadır (Cheung vd., 1996). Seçilecek olan rotalar her zaman en küçük maliyetli çözümü verecek şekilde belirlenir. Ayrıca rotalama probleminde ele

\footnotetext{
* ilgili yazar/Corresponding author: erdalaydemir@sdu.edu.tr, +90-246-211-1291
} 
alınması gereken diğer bir önemli konu ise taşıma sürelerinin en aza indirilmesidir.

En-RP, araç rotalama probleminin envanter yönetimi yaklaşımını kapsayan özel bir hali olarak bilinmektedir. Birçok problem gibi sistematik bir yapıya sahip olan envanter rotalama problemi de sürekli gelişme gösteren bir problemdir. En-RP, tüm bu süreçte, ayrıca müşterilerin başlangıç ve/veya maksimum envanter düzeylerini de takip ederek, sistem için envanter maliyetlerini de dikkate almaktadır. Bir dağıtım planı üzerinden çözüm aranan problemde, dağıtım planının her periyotu için ayrı ayrı araç rotalama problemi çalışmaktadır. $\mathrm{Bu}$ nedenle, problem boyutu çok fazla genişleyen bir yapıya dönüşmektedir. Araç rotalama probleminin yanında envanter seviyeleri ile ilgili ilave kısıtlar içermesi nedeniyle problem NP-Zor problemler sınıfında yer almaktadır (Cheung vd., 1996; Eryavuz ve Gencer, 2001; Speranza ve Bertazzi, 2013).

İşletmeler açısından büyük öneme sahip bu problem türü ile, araç rotalama problemi ve envanter yöntemi kapsamından kaynaklı bazı temel sorulara cevap aranir:

- Müșterilere teslimatlar ne zaman yapılacak?

- Müşterilere gönderilecek malzeme/ürün miktarı ne kadar olacak?

- Hangi rotalar kullanılacak?

Yukarıda bahsedilen üç ana madde En-RP için de önemli bir başarı performans göstergesidir. Ancak problemin kendine özgü yapısı yeni varsayımları da ortaya koymuştur (Speranza ve Bertazzi, 2013):

- Müşterilere yapılacak günlük teslimatlar müşterilerde stok oluşturmayacak şekilde yapılmalıdır.

- Günlük müşteri tüketimi ve ilk ihtiyaçlar bilinmelidir.

- Önemli bir kısıt olan araç kapasitesi, araç için belirlenen rota dolaşımı için yeterli zamana sahip olmalıdır.

- Mevcut araçlar belirlenen rotalar için seyahat edebilecek yeterli sayıda olmalıdır.

Çalışmanın ikinci bölümünde En-RP için geliştirilen politikalar ve üçüncü bölüm de ise; problemin matematiksel model yapısı üzerinde durulmuştur. Dördüncü bölümde detaylı bilimsel yazın taraması ve son bölümde ise En-RP için yeni araştırma alanlarının neler olabileceğine değinilmiştir.

\section{Geliştirilen Politikalar}

En-RP için, önemli bir aşama envanter yönetimi kapsamında dağıtım planının belirlenmesidir. Dağıtım planları karar vericilerin uygulayacağı birtakım politikalara göre değişkenlik göstermektedir. Her politikanın kendine has özellikleri tüm planlama ufku boyunca geçerli kılınabileceği gibi zaman zaman bazı öngörülen özel durumlarda ise bu politikaların genellikle ikisi ve/veya daha fazlası aynı anda ele alınabilmektedir.

Sevkiyat süreleri, planlama ufku göz önüne alındığında optimal dağıtım politikaları; servis zamanları, teslim miktarları ve güzergahlar tarafından belirtilir. Herhangi özel bir yapı olmadan optimal dağıtım politikasını belirleme son derede zor olabilir. Ayrıca bir politikanın yapısını kısıtlamak için uygulamadan kaynaklı nedenler de ortaya çlkabilmektedir. Uygulanacak politika belirlenmiş ise, politikanın sahip olduğu yapıya göre envanter rotalama problemi optimal veya sezgisel bir yapıya dönüşmektedir. Aşağıda envanter rotalama problemi için geliştirilmiş ve en çok kullanılan politikalara yer verilmiştir (Bertazzi ve Speranza, 2012):

- Sifir Envanter (Zero Inventory Ordering): Müşterilerin envanter düzeyleri 0 (sıfır) noktasına geldiği anda yeniden siparişin verdikleri politika türüdür.

- Periyodik (Periodic): Herhangi bir operasyon için gerekli $\mathrm{t}$ zamanında bir $\mathrm{P}$ sayısında periyot bulunarak, $0 \leq t \leq P$, operasyon $t+k P, k=1,2, \ldots$ sürede tekrarlanir.

- Frekans Tabanll (Frequency-based): $\mathrm{Bu}$ periyodik politika bir veya birden fazla frekans tabanlı olarak performans gösterir. Her frekansta sevkiyat arası süreler sabittir. Tek frekans aralığı varsa, sevkiyatlar arası süre sürekli veya kesikli olabilir. Farklı sayıda frekans aralığı varsa, bu sevkiyat süreleri tam sayılı değerler alırlar.

- Tam Yük Sevkiyat (Full Load Shipments): Sevkiyatta kullanılan araçların tam kapasite/yük altında kullanımı hedeflenir.

- Doğrudan Nakliye (Direct Shipping): Dağıtıcılardan her bir müşteriye bağımsız ve doğrudan sevkiyat ile dağıtım yapılır.

- İhtiyac Kadar Siparis (Order-up-the level): Dağıtım her zaman müșterinin ihtiyacı kadar gerçekleştirilir.

- Maksimum Seviye (Maximum Level): İhtiyaç kadar sipariş politikasının genelleştirilmiş bir halidir. Her bir müșteri maksimum seviyesini belirler. Dağıtım yapılacak miktar müşterinin belirlediği maksimum seviyeden daha büyük olmayacak şekilde gerçekleştirilir.

- $\quad$ Sabit Bölümleme (Fixed Partition): Dağıtım yapılacak müșteriler ayrı ayrı ve birbirinden bağımsız bir küme halinde belirlenir. Diğer bir deyișle, herhangi bir yol ile aynı kümenin müşterileri ziyaret edilir. Genellikle bölümleme müșterilerin coğrafi konumları dikkate alınarak gerçekleştirilir.

- Bölümleme Tabanlı (Partition-based): Bu tip politika sabit bölümleme politikasının genelleştirilmiş hali olarak karşımıza çıkar. Yine herhangi bir rota kullanılarak müşteriler 
ziyaret edilir. Aynı zamanda müşteriler iki veya daha fazla özel kombinasyonlarla kümelenebilmektedir.

Burada her bir politika incelenen envanter rotalama probleminin kapsamına göre birlikte ve/veya ayrı ayrı ele alınabilmektedir.

\section{Matematiksel Model}

Bu kısımda matematiksel model, konuyu Speranza ve Bertazzi (2013) yaptıkları tanımlama şeklinde ele almak uygun olacaktır. Model kurma tek ve çok araç kullanım şekline göre gerçekleştirmişlerdir.

\section{$\underline{\text { Klsaltmalar }}$}

H : Planlama ufku

$T \quad$ : Zaman periyotdu $(1, \ldots . \mathrm{H})$

$N \quad$ : Dügüm kümesi

$N^{\prime} \quad$ : Müşteri kümesi

$c_{i j} \quad$ : i. noktadan j.noktaya taşıma maliyeti

$U_{i} \quad:$ i. müşterinin maksimum envanter düzeyi

$r_{0 t} \quad$ : Depoda bulunan envanter düzeyi

$r_{i t} \quad$ : Müşteride bulunan envanter düzeyi

$Q \quad$ : Araç kapasitesi

$I_{i 0} \quad$ : i. müşterinin başlangıç envanter düzeyi

$h_{i} \quad$ : Envanter bulundurma maliyeti

$z_{i t} \quad$ : Müşteri ziyaret edilmişse 1, diğer durumlarda 0 değeri atanır.

$x_{i t} \quad$ : i. müşteriye t. zamanda gönderilen miktar

$y_{i j}^{t} \quad$ : ij ayrıtı kullanılmışsa 1, diğer durumlarda 0 değeri atanır.

$z_{0 t} \quad:$ t. günde en az 1 müşteriye dağıtım yapılıp, depo ziyaret edilmişse 1 değeri atanır.

$z_{i t} \quad:$ t. günde en az 1 müşteriye dağıtım yapılıp, o müşteri ziyaret edilmişse 1 değeri atanır.

$z_{s t} \quad$ : s. müşteriye dağıtım yapılmış ve o periyotta başka tura eklenmeme durumunda 1 değeri atanır.

\section{Çok Araçlı Modelde}

K : Araç seti

$\mathrm{z}_{\mathrm{it}}^{\mathrm{k}} \quad$ : i. müşteri k. arabayla ziyaret edilmişse 1, diğer durumda 0 değeri atanır.

$\mathrm{y}_{\mathrm{ij}}^{\mathrm{kt}} \quad$ : ij ayrıtının $\mathrm{k}$ aracı tarafından kaç kez ziyaret edildiğini ifade eder.

\subsection{Tek Araçlı En-RP Matematiksel Modeli}

Tek araçlı envanter rotalama problemi sadece bir günlük bir rota oluşturma durumunda karşımıza çlkmaktadır. Bu rota ise sadece bir araca ihtiyaç duymaktadır. Aşağıda tek araçlı En-RP için geliştirilmiş bir matematiksel model verilmiştir (Speranza ve Bertazzi, 2013):

$$
\min \sum_{t \in T} \sum_{i \in N} h_{i} I_{i t}+\sum_{t \in T} \sum_{i \in N} \sum_{j \in N . j>i} c_{i j} y_{i j}^{t}
$$

$$
\begin{aligned}
& I_{0 t}=I_{0, t-1}+r_{0 t}-\sum_{i \in N^{\prime}} x_{i t} \quad \mathrm{t} \in \mathrm{T} \\
& I_{i t}=I_{i, t-1}+x_{i t}-r_{i t} \quad \mathrm{i} \in \mathrm{N}^{\prime}, \mathrm{t} \in \mathrm{T} \\
& I_{i t} \geq 0 \quad \mathrm{i} \in \mathrm{N}, \mathrm{t} \in \mathrm{T} \\
& I_{i t} \leq U_{i} \quad \mathrm{i} \in \mathrm{N}^{\prime}, \mathrm{t} \in \mathrm{T} \\
& \sum_{i \in N^{\prime}} x_{i t} \leq Q z_{0 t} \quad \mathrm{t} \in \mathrm{T} \\
& x_{i t} \leq U_{i z_{i t}} \quad \mathrm{i} \in \mathrm{N}^{\prime}, \mathrm{t} \in \mathrm{T} \\
& \sum_{j \in N . j>i} y_{i j}^{t}+\sum_{j \in N . j<i} y_{j i}^{t}=2 z_{i t} \quad \mathrm{i} \in \mathrm{N}, \mathrm{t} \in \mathrm{T} \\
& \sum_{i \in S} \sum_{j \in S . j>i} y_{i j}^{t} \leq \sum_{i \in S} z_{i t}-z_{s t} \mathrm{~S} \subseteq \mathrm{N}^{\prime} \quad \mathrm{s} \in \mathrm{S}, \mathrm{t} \in \mathrm{T} \\
& \mathrm{X}_{\mathrm{it}} \geq 0 \quad \mathrm{i} \in \mathrm{N}^{\prime}, \mathrm{t} \in \mathrm{T}^{t} \\
& y_{i j}^{t} \in\{0,1\} \mathrm{i} \in \mathrm{N}^{\prime}, \mathrm{j} \in N^{\prime}, \mathrm{j}>\mathrm{i}, \mathrm{t} \in \mathrm{T} \\
& \mathrm{y}_{0 j}^{t} \in\{0,1,2\} \quad \mathrm{j} \in \mathrm{N}^{\prime}, \mathrm{t} \in \mathrm{T} \\
& \mathrm{Z}_{\mathrm{it}} \in\{0,1\} \quad \mathrm{i} \in \mathrm{N}, \mathrm{t} \in \mathrm{T}
\end{aligned}
$$

(3.1) numaralı eşitlik toplam maliyeti en küçükleyen amaç fonksiyonudur. (3.2) ve (3.3) numaralı eşitlikler ise, müşterilerin ve deponun envanter düzeyini belirleyen kısıtlardır. (3.4) numaralı eşitlik stoksuzluğu engelleyen kısıt, (3.5) numaralı eşitlik müşterilerin maksimum envanter düzeylerini aşmasını engelleyen kısıtları temsil eder ve (3.6). eşitlik ise gönderilen miktarların araç kapasitesini aşmasını engelleyen kısıttır. (3.7). eşitlikte i. müşteri eğer rotada ise ona dağıtım yapılmasını sağlarken (3.8) ve (3.9). eşitlikler ise rotalama kısıtlarıdır. Benzer şekilde, (3.10), (3.11), (3.12) ve (3.13) numaralı eşitlikleri ise karar kısıtlarıdır.

\section{2. Çok Araçlı En-RP Matematiksel Modeli}

Çok araçlı ERP modeli tek araçlı En-RP'nin genelleştirilmiş şeklidir. Tek araçlı envanter rotalama da tek araç mevcutken çok araçlı envanter rotalama probleminde bu tek araç, araç filosuna dönüşmektedir (Speranza ve Bertazzi, 2013).

$$
\begin{aligned}
& \min \sum_{t \in T} \sum_{i \in N} h_{i} I_{i t}+\sum_{k \in K} \sum_{t \in T} \sum_{i \in N} \sum_{j \in N . j>i} c_{i j} y_{i j}^{k t} \\
& I_{0 t}=I_{0, t-1}+r_{0 t}-\sum_{k \in K} \sum_{i \in N^{\prime}} x_{i t}^{k} \quad \mathrm{t} \in \mathrm{T} \\
& \mathrm{I}_{\mathrm{it}}=\mathrm{I}_{\mathrm{i}, \mathrm{t}-1}+\sum_{k \in K} x_{i t}^{k}-r_{i t} \quad \mathrm{i} \in \mathrm{N}^{\prime}, \mathrm{t} \in \mathrm{T} \\
& \mathrm{I}_{\mathrm{it}}>0 \quad \mathrm{i} \in \mathrm{N}, \quad \mathrm{t} \in T \\
& I_{i t} \leq U_{i} \quad \mathrm{i} \in \mathrm{N}^{\prime}, \mathrm{t} \in \mathrm{T} \\
& \sum_{i \in N^{\prime}} x_{i t}^{k} \leq Q z_{0 t}^{k} \quad \mathrm{k} \in \mathrm{K}, \mathrm{t} \in \mathrm{T} \\
& \mathrm{X}_{i t}^{k} \leq U_{i} z_{i t}^{k} \quad \mathrm{i} \in \mathrm{N}^{\prime}, \quad \mathrm{k} \in \mathrm{K}, \mathrm{t} \in \mathrm{T} \\
& \sum_{k \in K} z_{i t}^{k} \leq 1 \quad \mathrm{i} \in \mathrm{N}^{\prime}, \quad \mathrm{t} \in \mathrm{T}
\end{aligned}
$$




$$
\begin{aligned}
& \sum_{j \in N . j>i} y_{i j}^{k t}+\sum_{j \in N . j<i} y_{j i}^{k t}=2 z_{i t}^{k} \quad \mathrm{i} \in N^{\prime}, \mathrm{k} \in \mathrm{K}, \mathrm{t} \in T \\
& \sum_{i \in S} \sum_{j \in S . j>i} y_{i j}^{k j} \leq \sum_{i \in S} z_{i t}^{k}-z_{s t}^{k} \quad \mathrm{~S} \subseteq \mathrm{N}^{\prime}, \mathrm{s} \in \mathrm{S}, \mathrm{k} \in \mathrm{K}, \mathrm{t} \in \mathrm{T} \\
& x_{i t}^{k} \geq 0 \quad \mathrm{i} \in \mathrm{N}^{\prime}, \mathrm{k} \in \mathrm{K}, \mathrm{t} \in \mathrm{T} \\
& \mathrm{y}_{i j}^{k t} \in\{0,1\} \quad \mathrm{i} \in \mathrm{N}^{\prime}, \mathrm{j} \in \mathrm{N}^{\prime}, \mathrm{j}>\mathrm{i}, \mathrm{k} \in \mathrm{K}, \mathrm{t} \in \mathrm{T} \\
& \mathrm{y}_{0 j}^{k t} \in\{0,1,2\} \quad \mathrm{j} \in \mathrm{N}^{\prime}, \mathrm{k} \in \mathrm{K}, \mathrm{t} \in \mathrm{T} \\
& \mathrm{z}_{i t}^{k} \in\{0,1\} \quad \mathrm{i} \in \mathrm{N}, \mathrm{k} \in \mathrm{K}, \mathrm{t} \in \mathrm{T}
\end{aligned}
$$

(3.14) numaralı eşitlik toplam maliyeti en küçükleyen amaç fonksiyonudur. (3.15) ve (3.16) numaralı eşitlikler müşterilerin ve deponun envanter düzeyini belirleyen kısıtlardır. (3.17) numaralı eşitlik stoksuzluğu engelleyen kısıt ve (3.18) numaralı eşitlik ise, müşterilerin maksimum envanter düzeylerini aşmasını engelleyen kısıttır. Eşitlik (3.19) da gönderilen miktarların araç kapasitesini aşmasını engellenirken, eşitlik (3.20)'de ise, i. müşteri eğer rotada ise müşteriye dağıtım yapılmasını sağlanır. (3.21) numaralı eşitlik, bir müşterinin en fazla 1 araçla dağıtım yapılmasını sağlayan kısıttır. (3.22). ve (3.23). eșitlikler ise rotalama kısıtlarıdır. Benzer șekilde (3.24), (3.25), (3.26) ve (3.27) numaralı eşitlikler karar durumlarını sınırlandırır.

$\mathrm{Bu}$ modellere ek olarak bilimsel yazında zaman pencereleri, çoklu depolar ve yol süresi kısıtlamalarını içeren matematiksel modellere sıklıkla rastlanılmaktadır.

\section{Bilimsel Yazın Taraması}

Envanter rotalama problemi üzerine yapılan çalışmalara bakıldığında araştırmacıların envanter rotalama problemini temelde deterministik veya stokastik süreçler/modeller olarak iki ayrı yapıda çalışıldığı görülmektedir. En-RP konusunda ve tez çalışması ile ilgili seçilmiş bilimsel yazın örnekleri Çizelge 2.1'de verilmiştir.

Bilimsel yazın incelendiğinde, En-RP; doğrusal programlama, karma tam sayılı modeller ve Markov karar süreçleri ile birlikte ele alınmıştır. Ayrıca dalsınır, şebeke akışı, komşu arama ve genetik algoritma gibi birçok algoritmadan yararlanıldığı görülmektedir. Sezgiseller ve meta-sezgiseller, tabu araștırmaları, optimizasyon gibi yöntemler kullanılarak envanter rotalama probleminin gelişimi adım adım sağlanmıştır. Deterministik ve stokastik süreçlerle birlikte araç rotalama, gezgin satıcl, envanter kontrolü, satıcı yönetimli envanter rotalama gibi endüstri mühendisliğinin temel problemleriyle de birlikte çalışıldığı da gözlenmektedir.

En-RP'nin temeli sayılabilecek ilk çalışma belediyeler/yerel yönetimler için atık/çöp toplama sorunuyla ortaya çıkmıştır. Beltrami ve Bodin (1974) ortaya koydukları çalışmada, New York şehrinin haritası üzerinde çöp toplama noktaları ve güzergâhlar oluşturulmuştur. Problemdeki amaç, araç kapasitesi ve zamanlama kısıtı yanında güzergâhta bulunan tüm çöp noktalarına uğrayarak gerekli araç sayısını en aza indirecek güzergâhı belirlemektir. Bu çalışmada gezgin satıcı problemi ve Clarke-Wright tasarruf algoritması prosedürleri uygulanmıştır. Blumenfeld vd. (1985) çalışmalarında ulaştırma, envanter, üretim ve kurulum maliyetleri arasındaki ilişkiyi analiz ederek en iyi nakliye politikalarını belirlemeye çalışmışlardır.

Trudeau ve Dror (1992) ise, envanter rotalama probleminde bir rota üzerinde gerçek talebin araç kapasitesini aştığında rotada meydana gelebilecek başarısızlı durumunun olasılık analizini yapmışlardır. Minkoff (1993) envanter rotalama problemini Markov karar süreci olarak modelleyerek sezgisel bir yaklaşım önermiştir. Chandra ve Fisher (1994), üretim ve dağıtım planlaması üzerine bir çalışma ortaya koymuşlardır. Bramelve Simchi-Levi (1995) rotalama ve envanter rotalama problemini baz alarak bu çalışmalarını "Kapasite Yoğunlaştırıcı Yer Sorunu" olarak modellemişlerdir. Campbell vd. (1998), envanter rotalama problemi satıcı yönetimli envanter (vendor managed inventory replenishment (VMI)) problemi şeklinde ele almışlardır. Envanter rotalama probleminin temel karakteristikleri, VMI şeklinde geliştirilerek lojistik planlama sistemleri için yeni bir bakış açısı ortaya koymaktadır. Kleywegt vd. (1998) yaptıkları çalışmada, envanter rotalama probleminin, birçok müşteri ile bağlantılı olmasından dolayı, modelleme zorluğundan bahsetmektedirler. Bard vd. (1998) En-RP'yi dal-kesme algoritması içeren üç sezgiselle sunmuşlardır. Jaillet vd. (2002) ise yaptıkları çalışmada, belirli bir plan ufkunda artan maliyet yaklaşımlarını ortaya koymuşlardır. Burada envanter rotalama problemi bir Markov karar süreci kullanılarak modellenmiş ve En-RP'ye yeni bir yaklaşım yöntemi sunulmuştur. Benzer şekilde, Kleywegt vd. (2002), envanter rotalama problemini Markov karar süreci olarak modellenmiştir. Sonuçlar doğrudan teslimatlı bir envanter rotalama problemi olarak sunulmuştur. Causineau-Ouimet (2002) yaptığı çalışmada bir tabu arama sezgiseli önermiş ve önerdiği algoritmayı rastgele oluşturulmuş bir model üzerinde test etmiştir. Yine Kleywegt vd. (2004), envanter rotalama problemine satıcı yönetimli envanter problemi olarak ele almışlar ve yenileme yaklaşımı kullanılarak müşterilerin ne kadarlık malzemeyi hangi süre ve zamanlarda yenileneceği ve bunu en ekonomik süre ve maliyetle nasıl gerçekleştirilebileceğinin çözümünü araştırmışlardır. Bunun için kurulan stokastik (olasıklı) envanter rotalama modelini bir Markov karar süreci olarak ele almışlardır.

Adelman (2004) ise yaptığı çalışmada, doğrusal programlama yaklaşımı kullanarak stokastik envanter rotalama problemine yeni bir yaklaşım sunmaktadır. İki tür doğrusal programlama yaklaşımı önerilmiştir; ilk olarak Markov karar süreci kullanılarak kontrol 
süreci denetim altına alınmaya çalışılmış ve ikinci olarak optimal değer fonksiyonu yerine tek müşteri stok değer fonksiyonlarının toplamı şeklinde yazmıştır. Envanter özelliklerini ve ekonomik verileri içinde barındıran bir stokastik envanter rotalama problemi şeklinde sunmuştur.

Çizelge 2.1. Bilimsel yazın örnekleri

\begin{tabular}{|c|c|}
\hline Literatüre Katkı Veren Yazar & Alan ve Özellikleri \\
\hline Beltrami ve Bodin (1974) & $\begin{array}{l}\text { Envanter rotalama probleminin temeli, Gezgin Satıcı Problemi, Clarke- } \\
\text { Wright Algoritması }\end{array}$ \\
\hline Bell vd. (1983) & $\begin{array}{l}\text { En Kısa Yol Algoritması, Optimizasyon, Lagrange Algoritması, Karışık } \\
\text { Tamsayılı Programlama }\end{array}$ \\
\hline Minkoff (1993) & Markov Karar Süreci, Sezgisel Yaklaşım \\
\hline Campbell vd. (1998) & Satıcı Yönetimli En-RP \\
\hline Kleywegt vd. (1998) & Markov Karar Süreci \\
\hline Cousineau-Ouimet (2002) & Markov Karar Süreci \\
\hline Kleywegt vd. (2004) & Markov Karar Süreci, Stokastik Model \\
\hline Adelman (2004) & Markov Karar Süreci, Stokastik Süreç \\
\hline Liu (2006) & Sezgisel Yaklaşım, Karmaşık Tamsayılı Modelleme \\
\hline Aghezzaf vd. (2006) & Doğrusal Olmayan Tam Sayılı Modelleme \\
\hline Zhao vd. (2006) & Tabu Arama \\
\hline Savelsbergh vd. (2007) & Lineer Programlama, Stokastik Modelleme \\
\hline Savelsbergh vd. (2008) & Tamsayılı Modelleme, Açgözlü Sezgisel Algoritma \\
\hline Archetti vd. (2008) & Meta-sezgisel Yaklaşım, Tabu Araştırma, Tamsayı Modelleme \\
\hline Hvattum ve Løkketangen(2009) & Markov Karar Süreci,Sezgisel Yaklaşım \\
\hline Sadok vd. (2010) & Genetik Algoritma, Yerel Arama Algoritması \\
\hline Moin vd. (2010) & Genetik Algoritma \\
\hline Huang ve Lin (2010) & Karınca Kolonisi Optimizasyonu \\
\hline Geiger vd. (2011) & Yerel Arama Algoritması, Meta-sezgisel Yaklaşım \\
\hline Coelho vd. (2011) & Komşu Sezgisel Arama Algoritması \\
\hline Laporte vd. (2011) & Dal ve Sinır Algoritması \\
\hline Bertazzi vd. (2012) & Sezgisel Yaklaşım, Tabu Araştırması, Tamsayı Modelleme \\
\hline Coelho vd. (2012) & $\begin{array}{l}\text { Meta-sezgisel Yaklaşım, Tamsayılı Doğrusal Programlama, Komşu Arama } \\
\text { Algoritması }\end{array}$ \\
\hline Song vd. (2013) & Sezgisel Yaklaşım \\
\hline Bertazzi vd. (2013) & Tek ve Çok Araçlı Envanter Rotalama Problemleri \\
\hline Rahim vd. (2014) & Stokastik Yaklaşım \\
\hline Archetti ve Speranza (2014) & $\begin{array}{l}\text { Araç Rotalamada Mat-Sezgisel Yaklaşımlar, Karışık Tamsayılı Doğrusal } \\
\text { Programlama }\end{array}$ \\
\hline Huber vd. (2015) & İki amaçlı En-RP, Referans Noktası, Pareto Optimum \\
\hline Archetti ve Speranza (2016) & $\begin{array}{l}\text { Satıcı Yönetimli En-RP, Perakende Yönetimli En-RP, Sezgisel Algoritma } \\
\text { Yaklaşımı }\end{array}$ \\
\hline Schönberger (2016) & $\begin{array}{l}\text { Karışık Tamsayılı Doğrusal Programlama, Çok Periyotlu Araç Rotalama } \\
\text { Problemi }\end{array}$ \\
\hline Aghezzaf vd. (2016) & $\begin{array}{l}\text { Dal Sınır Algoritması, Satıcı Yönetimli En-RP, Tek Araçlı Döngüsel En-RP, } \\
\text { Gezgin Satıcı Problemi, }\end{array}$ \\
\hline
\end{tabular}

Liu (2006) çalışmasında iki farklı yaklaşım yer almaktadır. İlk olarak envanter rotalama problemini karma tam sayılı doğrusal model ile birlikte vermiştir. Birinci yaklaşımda elde edilen veriler ilk modeldeki optimal sonuçları verdiği görülmüştür. İkinci yaklaşımda ise doğrusal sevkiyat verimsizliğini çözmeye dair bir çözüm önermiștir. Burada teslimat birleştirme sorunu ek kısıtlamaları olan bir kapasite kısıtlı ulaştırma problemi olarak ele alınmış ve sezgisel bir rotalama algoritması ile çözülmüștür. Aghezzaf vd. (2006) yaptıkları çalışmada, talep oranlarının sabit ve klasik ekonomik sipariş miktarı modelinin kullanıldığı durumlarda envanter rotalama problemi için uzun dönemli yeni bir model önermişlerdir. Araç rotaları ve araç tur sayılarının geliștirilmesi ve genișletilmesi Doğrusal olmayan tam sayılı programlama yaklaşımı ile kısa turların uzun turlarla karşılaştırılarak çözülmüştür. Zhao vd. (2006) ise, araç rotalama ve envanter kontrolü problemlerini bir araya getirerek dağıtım sistemlerindeki performansların iyileştirilmesine yönelik bir çalışma ortaya koymușlardır. Çalıșmada tabu arama algoritması çözüm yöntemi olarak önerilmiştir. Sabit bölme politikası, perakendecilerin en iyi bölümleme bölgelerini saptamak için tasarlanmıș ve önerilen algoritmanın etkinliği yapılan hesaplamalarda gösterilmiştir.

Savelsbergh vd. (2007), envanter rotalama problemi için iki önemli gerçek hayat karmaşıklığı üzerinde 
durmuşlardır. Bunlar sınırlı ürün durumları ve müşteri tekrar turlarının önlenmesidir. Çalışmada doğrusal programlama tabanlı yenilikçi rassal bir açgözlü (greedy) algoritma geliştirilmiştir. Savelsbergh vd. (2008), kısa ve uzun uzaklıkları çözmek ve analiz etmek için tamsayılı programlama tabanlı optimal sonuç veren açgözlü bir sezgisel algoritma önermişler ve büyük ölçekli problemlerin çözümü için önerilen bu algoritmanın çözüm etkinliği detaylıca verilmiştir.

Archetti vd. (2008) ise, En-RP’nin çözümü için tabu arama ve tam sayll modellemenin bir arada kullanılması ile oluşturulmuş bir meta-sezgisel yöntem kullanmışlardır. Tabu arama algoritmasının karmaşık yapılı olan araç rotalama problemlerinin çözümünde çok etkili olması nedeniyle aynı şekilde En-RP içinde gerekli olduğunu belirtmişlerdir. Geliştirilen yöntem analiz sonuçları, ortaya çıkan hataların \%1'in altına indirmeyi başardığını göstermiştir. Hvattum ve Løkketangen (2009a) yaptıkları çalışmada, sonlu planlama periyodunda bir senaryo varlığında envanter rotalama problemine Markov karar süreci ile çözüm aramışlardır. Devamında ise, Hvattum ve Løkketangen (2009b) verilen bu senaryoyu sezgisel bir temelle yeniden tasarlamışlardır.

Li vd. (2009) çalışmalarında, teslim sıklığı sinırlamaları ve sinırsız planlama ufkunda yer alan envanter rotalama problemini modellemişlerdir. Doğrudan nakliye stratejisi bir sistem parametresi fonksiyonu olarak ele alınmış ve doğrudan nakliye etkinliğinin araç kapasitesinin karekökü olduğunun bir ispatı yapılmıştır. Çalışma, işletmelere hangi durumlar varlığında doğrudan nakliye daha mantıklıdır onun cevabını vermeye yöneliktir ve analitik yöntemler ile sistem parametrelerini ayarlama yoluyla, mümkün dağıtım sisteminin performansını iyileştirmenin nasıl mümkün olacağına cevap aramaktadır. Bard ve Nananukul (2009a) ise, En-RP'yi çözmek için günlük teslimat miktarları tahmini ve planlama ufkunda iki aşamalı bir algoritma önermişlerdir. Bard ve Nananukul (2009b) bu çalışmalarında ise, aynı problem için reaktif tabu arama merkezli bir algoritma sunmuşlardır. Huang ve Lin (2010) ise, envanter rotalama problemine karınca kolonisi optimizasyonu yöntemini uygulamışlardır.

Sadok vd. (2010) çalışmalarında, her bir araç çoklu tur yapacak şekilde organize edilmiş ve araç bazı teslim yerlerini ziyaret ettikten sonra diğer teslimi yapılmayan yerleri ziyaret etmeden depo konumuna geri dönebilmektedir. Bu sisteme uygun olarak özel bir geçiş operatörü ile bir genetik algoritma modeli önerilmiş ve aynı zamanda bu algoritma her tekrarda bir yerel arama algoritması ile melezleştirilmiştir. Çalışmada algoritmanın etkinliğini göstermek için çok sayıda veri seti için çözüm elde edilmiştir. Bard ve Nananukul (2010), dal-ve-fiyat algoritması kapsamında kesin ve sezgisel prosedürleri birleştiren melez bir yöntem ortaya koymuşlardır. Moin vd. (2010) ise, dağıtımın birinci güzergâhın ikinci strateji olarak belirlendiği bu iki noktaya dayanan melez bir genetik algoritma geliştirmişlerdir. Problemin matematiksel modeli verilmiş olup sınırlı bir zaman altında model, alt ve üst sınırları için CPLEX 9.1'de çalıştırılmıştır. Grønhaug vd. (2010) deniz ulaştırma alanında envanter rotalama problemi üzerine durmuşlardır. $\mathrm{Bu}$ çalışmalarını dal-fiyat algoritması kullanarak çözümlemişlerdir.

Geiger vd. (2011), iki-amaçlı envanter rotalama problemi olarak elde aldıkları çalışmada önceki araştırmaların aksine En-RP çok amaçlı bir optimizasyon problemi olarak adlandırılmış ve pareto optimal çözümü ile desteklenmiştir. Çözüm bir yerel arama meta-sezgisel bir yöntemle geliştirdikleri test veri setleri için sayısal sonuçlar elde edilerek verilmiştir. Coelho vd. (2011) yaptıkları çalışmada, envanter rotalama problemi çözümüne uyarlamalı komşu arama sezgiseli önermişlerdir. Bu yöntem, araç rotalarını manipüle ederek teslimat miktarlarını ve aktarmalarını ağ akış algoritması ile belirlemektedir. Önerilen yaklaşım test problemine ait 4 farklı türü çözebilmektedir. En-RP'nin maksimum seviye ve ihtiyaç kadar seviye politikaları için çözüm yapabilmektedir. Laporte vd. (2012) ise, En-RP'nin farklı yaklaşımları için dal-sınır algoritması önermiştir. Çok araçlı En-RP çözümünde aktarma özellikleri dikkate alınarak homojen ve heterojen filolar kullanılmıştır. Bu kriterlere uyan örnekler için analizler yapılmıştır. Bertazzi vd. (2012), iki farklı yenileme politikası üzerine durmuştur. Bu politikalar maksimum seviye ve yeteri kadar sipariş politikalarıdır. Ulaşım maliyetleri gidilecek yollarla, stok tutma maliyeti ise dağıtıcı ve müşterinin elinde bulunan malzemeyle orantılıdır. Çalışmanın amacına uygun olarak önerilen sezgisel yaklaşım, tabu arama şeması ile birleştirilerek tamsayılı programlama modeli olarak verilmiştir. Optimal çözüm detaylı bir şekilde sunulmuştur.

Coelho vd. (2012), çok araçlı En-RP için meta-sezgisel bir tam sayll doğrusal programlama modeli önermişler ve komşuluk arama algoritması kullanarak problemi sezgisel bir alt problem olarak çözmüşlerdir. Önerilen algoritma maliyet ve kalite arasında iyi bir uzlaşma sunan çözüm üretmektedir. Farklı stok politikalarında rotalama kararlarının ve teslimat boyutlarının etkileri gözlemlenmeye çalışılmıştır. Bertazzi vd. (2012) yaptıkları çalışmada, envanter rotalama problemi temel olarak anlatılmaktadır. Envanter rotalama problemi araç rotalama ve envanter yönetimi problemlerinin bir birleşimi olarak düşünülmüş ve dağıtım ağlarının nasıl yönlendirileceği ile yönetileceği hakkında örnekler ve uygulamalara yer verilmiștir. Doğrudan sevkiyat ve bağlantılı sevkiyat problemlerine de değinilmiştir. Envanter rotalama problemi için farklı bakış açıları sunulmuştur. 
Solyalı ve Süral (2012) ise, envanter rotalama probleminin zorlu yanlarını karma tam sayılı programlama ile modelleyerek, çözümü için dal-sınır algoritması önermişlerdir. Michel ve Vanderbeck (2012), envanter rotalama probleminde rotalama maliyetini en aza indirmek için dal-kesme ve fiyat algoritmalarını yerel arama algoritması ile birleştirerek bir sezgisel yaklaşım ortaya koymuşlardır. Shukla vd. (2013) çalışmalarında, probleme evrimsel algoritmalara dayalı bir çözüm metodolojisi önermişlerdir. Song vd. (2013) ise, çeşitli pratik özelliklerin olduğu bir En-RP için esnek bir model yapısı sunmuşlardır. Bu yapı sezgisel ve basit bir algoritmaya dayanmaktadır. Uygulama olarak ise denizcilik envanter rotalama problemi olarak adlandırılmıştır. Önerilen modelleme ve algoritmik yaklaşım envanter rotalama problemi için etkili ve çözüm üretebilen önemli bir adım olmuştur.

Zied vd. (2013) çalışmalarında tedarikçi entegrasyonu için envanter rotalama çerçevesinde dağıtım ve stok politikaları üzerinde durmuşlardır. Statik rotaları kullanarak daha iyi bir dağıtım optimizasyonu sağlamışlardır. Bunun sonucunda dağıtım sistemleri performansında iyileşme sağlanmıştır. Coelho ve Laporte (2013) ise, envanter rotalama problemi için önemli olan dağıtım ve envanter yönetimi süreçlerine odaklanmışlardır. Çalışmada dal-sınır algoritmasını önermişlerdir. Homojen çok araçlı ve heterojen çok araçlı En-RP üzerinde bu algoritmayı çözümlemişlerdir. Bertazzi vd. (2013), envanter rotalama probleminde tek araç ve çok araç yaklaşımlarını dikkate almıştır. En-RP'ye genel bir bakış açısı ortaya koyan çalışmada, gezgin satıcı probleminden periyodik araç rotalama probleminin de içinde olduğu ve bu problemlerin envanter rotalama problemi ile ilişkilendirilip ve farklılıkları gösterilmektedir. Tek araçla ve çok araçla envanter rotalama problemi yaklaşımlarının matematiksel modelleri ve çalışmaya kadar envanter rotalama problemi için geliştirilmiş ve önerilmiş modeller ve problemler sınıflandırılmış ve bu problemlerin anlatıldığı bilimsel yazın özetlenmiștir.

Rahim vd. (2014) ise, çok periyotlu envanter rotalama problemi için stokastik sabit talep oranı kullanılarak bir yaklaşım önermişlerdir. Problem ilk olarak doğrusal karma tamsayılı stokastik model olarak ele alınmış ve deterministik eşdeğer yaklaşım modeli olarak kullanılmıştır. Çalışma, önemli iki alt problemi, araç rotalama ve envanter atama, ayrıştırmayı amaçlamaktadır. Envanter atama işlemi stokastik bir yaklaşımla, araç rotalama ise deterministik yaklaşımla ele alınmıştır. Örnekler Lagrange yöntemiyle verilmiştir. Avella vd. (2014) tek araçlı ve çok araçlı bir dağıtım ağında sınırlı araç kapasiteli envanter rotalama problemi üzerinde durmuşlardır. Maksimum seviye dağıtım politikası altında yeni bir model geliştirmişlerdir. Model dal-sınır algoritması ile çözülmüş ve modelin gücü artırılmıştır.
Coelho ve Laporte (2014) ise, En-RP için geliştirilmiş yeni modellerini talep ve mevcut kapasite ilişkisine göre ortaya koymuşlardır. İkili kümeleme ve iş çizelgesi problemleri için yeni yaklaşımlar ortaya koymuşlarıdır. Moin ve Halim (2014) tek depolu birden fazla müşterili bir envanter rotalama probleminde geri dönen siparişlerin çözümüne yönelik bir çalışma ortaya koymuşlar. Çalışmanın amacı nakliye maliyeti, stok maliyeti ve geri dönen sipariş maliyetlerini minimize etmektir. Yapay arı kolonisi yöntemi kullanılarak geliştirilmiş bir algoritma kullanılmıștır. Hemmati vd. (2015) ise, düzensiz bir nakliye dağıtım düzenini satıcı yönetimli envanter problemi olarak ele almışlar. Nakliye şirketi için 2 farklı sezgisel yöntem önerilmiş. Gemi taşımacılığı sektörü için ortaya koyulan çalışmada, ilk sezgisel envanter rotalamayı kargo rotalama problemine dönüştürmüştür. İkinci sezgisel ise kargo rotalama problemini komşu arama yöntemi ile çözmüştür. İterasyon şeklinde devam eden çözüm metodu tasarruf sağlayan bir çözüm yolu haline gelmiştir. Agostinho vd. (2015) bu çalışmada kısa deniz taşımacılığında petrol ürünlerinin dağıtımı ve depolanması gibi envanter yönetimini içeren bir problem üzerinde durmuşlardır. Hava koşulları ve öngörülemeyen bekleme süreleri gibi belirsizlikler üzerinde çalışılmıştır.

Schönberger (2016), belirli bir dönemde ya da dağıtılmış periyotlarda planlanan araç rotalama problemi üzerine bir çalışma ele alınmış. Seyahat sürelerini ve mesafe toplamını minimize edecek karmaşık tamsayılı doğrusal bir model önerilmiş. Kaynak dengeleme ve yönetimi konusunda da kapasite kısıtlı araç rotalama problemi üzerinde durulmuştur. Aghezzaf vd. (2016) ise, tek araçlı döngüsel En-RP üzerine bir çalışma ortaya koymuşlar. $\mathrm{Bu}$ çalışmadaki amaç, aynı anda taşıma ve stok maliyetlerini en aza indirerek çıktı fonksiyonunu maksimize etmektir. Tek araçlı döngüsel En-RP özellikleri üzerinde durularak matematiksel bir model geliștirilmiş. Geliştirilen bu model de dişbükey optimizasyon tekniği kullanılarak çözülmüştür.

Archetti ve Speranza (2016), farklı çözümlerin maliyetlerini ve özelliklerini karşılaştıran bir çalışma ortaya konulmuş. Tedarikçi yönetimli En-RP ve perakende yönetimli En-RP'yi çözmek için iki farklı yaklaşımla birlikte optimizasyon yöntemleri kullanılmış. Bu çözümleri sezgisel bir yaklaşımla ele almışlardır.

$\mathrm{Bu}$ çalışmada, En-RP için yapılan bilimsel yazın araştırması değerlendirildiğinde; problemin araç rotalama kısmı yanında daha çok envanter yönetimi kapsamında da farklı model yapılarının geliștirilmesinin de endüstriyel bir etkiye sahip olacağ olacağı/olabileceğinden sonraki bölümde bahsedilmiştir. 


\section{Sonuç ve Tartışma}

Bilimsel yazın araştırmasına göre; En-RP problem tipinde var olan belirli kısitların ve durumların yanı sıra karşılaşılabilecek olan farklı durumlarda incelenebilir. Dolayısıyla bu noktada, çalışma ile "Tedarik Zinciri Yönetimi" ve/veya "Envanter Rotalama" kapsamında ele alınacak problemlerin çözümünde mümkün yeni çalışma alanları ve gerçek hayat problemlerinde karşılaşılan özel durumların aşağıdaki gibi olacağı öngörülmektedir:

- Geri dönen ürün miktarları ve kalitesi,

- Özel siparişler,

- Dış belirsizlikler (Talep vb.),

- Dâhili belirsizlikler (Arz vb.),

- Filo arızaları,

- Beklenmeyen/Olağanüstü durumlar (Afetler, coğrafi durumları, v.b.),

- Müșteri Sınıflandırılması/Müşteri öncelikleri,

- Acil siparişler.

$\mathrm{Bu}$ durumlar çoğaltılabileceği gibi, araștırmacıların yukarıda verilen konulara öncelik vermeleri halinde endüstriyel ortamlara ve bilimsel yazına katkılar sağlayacakları düşünülmektedir.

\section{Teşekkür}

$\mathrm{Bu}$ çalışma, Süleyman Demirel Üniversitesi Bilimsel Araştırma Projeleri Koordinasyon Birimi tarafından 4355-YL1-15 nolu proje kapsamında desteklenmiştir.

\section{Conflict of Interest / Çıkar Çatışması}

Yazarlar tarafından herhangi bir çıkar çatışması beyan edilmemiştir.

No conflict of interest was declared by the authors.

\section{Kaynaklar}

Adelman D., 2004. A Price Directed Approach to Stochastic Inventory Routing. Transportation Science: INFORMS, 52, 499-514.

Aghezzaf E.H., Raa B., Van L. H., 2006. Modelling Inventory Routing Problems in Supply Chains of High Consumption Products. The European Journal of Operational Research, 169, 1048-1063.

Agostinho A., Marielle C., Alexandrino D., Lars M. H., 2015. A Maritime Inventory Routing Problem with Stochastic Sailing And Port Times. Computers \& Operations Research, 61, 18-30.

Ahmad H., Magnus S., Lars M. H., Henrik A., 2015. An Effective Heuristic for Solving a Combined Cargo And Inventory Routing Problem in Tramp Shipping. Computers \& Operations Research, 64, 274-282.

Archetti C., Bertazzi L., Hertz A., Speranza M. G., 2008. A Hybrid Algorithm for an Inventory Routing Problem. EU Meeting, October 23-24, Troyes.
Archetti C., Bertazzi L., Hertz A., Speranza M. G., 2012. A Hybrid Heuristic for an Inventory Routing Problem. INFORMS Journal on Computing, 24,101116.

Archetti C., \& Speranza M. G., 2014. A Survey On Matheuristics for Routing Problems. The EURO Journal on Computational Optimization, 2(4), 223246.

Archetti C., Speranza M. G., 2016. The Inventory Routing Problem: The Value of Integration. International Transactions in Operational Research 23, 393-407.

Aydemir E., 2013. Kusurlu Ürünleri İçeren Ekonomik Üretim Miktarı Modelinin Gri Sistem Teorisi Yaklaşımıyla Geliştirilmesi: Endüstriyel Bir Araştırma. Süleyman Demirel Üniversitesi, Fen Bilimleri Enstitüsü, Doktora tezi, 202s, Isparta.

Aydemir E., Bedir F., \& Özdemir G., 2013. Gri Sistem Teorisi ve Uygulamaları: Bilimsel Yazın Taraması. Süleyman Demirel Üniversitesi İktisadi ve İdari Bilimler Fakültesi Dergisi, 18(3). 187-200.

Aydemir E., Bedir F., Ozdemir G., \& Eroglu A., 2014. An EPQ Model With Imperfect Items Using Interval Grey Numbers. An International Journal of Optimization and Control: Theories \& Applications, 5(1), 21-32.

Ayvaz B., Kaçtığolu S., Varol K., 2014. Belirsizlikler Altında Tersine Lojistik A $\breve{g}$ Tasarımı Literatür Taraması. İstanbul Ticaret Üniversitesi Fen Bilimleri Dergisi, 24, 1-15.

Avella P., Boccia M., Wolsey L., 2014. Single-Period Cutting Planes for Inventory Routing Problems. CORE Discussion Papers, Belgium, 1-25.

Bard J.F., Huang L., Jaillet P., Dror M., 1998. A Decomposition Approach To the Inventory Routing Problem with Satellite Facilities. Transportation Science: INFORMS, 32, 189-203.

Bard J.F., Nananukul N., 2009a. Heuristicsfor A Multi Period Inventory Routing Problem with Production Decisions. Computers and Industrial Engineering, 57, 713-723.

Bard J.F, Nananukul N., 2009b. The Integrated Production Inventory Distribution Routing Problem. The Journal of Scheduling, 12, 257-280.

Bard J.F., Nananukul N., 2010. A Branch And Price Algorithm For An Integrated Production And Inventory Routing Problem. Computers \& Operations Research, 37, 2202-2217.

Bell W.J., Dalberto L.M., Fisher M.L., 1983. Improving The Distribution Of Industrial Gases With An On Line Computerized Routing And Scheduling Optimizer. Interfaces: INFORMS, 13(6), 4-23.

Beltrami E. J., Bodin L. D., 1974. Networks And Vehicle Routing For Municipal Waste Collection. Networks, 4, 65-94.

Bertazzi L., Speranza G.M., 2012. Inventory Routing Problems: An Introduction. European Journal of Transport and Infrastructure Research, 1, 307326.

Bertazzi L., Speranza G.M., 2013. Inventory Routing Problems With Multiple Customers. 
European Journal of Transport and Infrastructure Research, 2, 255-275.

Blumenfeld D.E., Burns L.D., Diltz J.D., Daganzo C.F., 1985. Analyzing Trade-Offs Between Transportation, Inventory And Production Costs On Freight Networks. Transportation Research, Part B Methodol, 19, 361-380.

Bramel J., Simchi-Levi D., 1995. A Location Based Heuristic For General Routing Problems. Operations Research: INFORMS, 43, 649-660.

Campbell A., Clarke L., Kleywegt A., Savelsbergh M., 1998. The Inventory Routing Problem. Fleet Management And Logistics, 95-113.

Chandra P., Fisher M.L., 1994. Coordination Of Production And Distribution Planning. The European Journal of Operational Research, 72, 503-517.

Cheung, R.K.M., Powell, W. B., 1996. Models And Algorithms For Distribution Problems With Uncertain Demands. Transportation Science Journal, 30(1), 43-59.

Coelho L.C., Laporte G., 2012. The Exact Solution of Several Classes of Inventory Routing Problems. Computers \& Operations Research, 40, 558-565.

Coelho L.C., Cordeau J.F., Laporte G., 2012. The Inventory Routing Problem with Transshipment. Computers \& Operations Research, 39, 2537-2548.

Coelho L.C., Cordeau J.F., Laporte G., 2012. Consistency in Multi Vehicle Inventory Routing. Transportation Research Part C: Emerging Technologies, 24, 270287.

Coelho L.C. , Cordeau J.F. , Laporte G., 2013. Thirty Years of Inventory Routing. Transportation Science: INFORMS, 48(1), 1-19.

Coelho L. C., Laporte G., 2014. Improved Solutions For Inventory-Routing Problems Through Valid Inequalities and Input Ordering. The International Journal of Production Economics, 155, 391-397.

Coelho L.C., Cordeau J.F., Laporte G., 2014. Heuristics For Dynamic and Stochastic Inventory Routing. Computers \& Operations Research, 52, 55-67.

Cousineau-Ouimet K., 2002. A Tabu Search Heuristic For The Inventory Routing Problem. Proceedings of 37th Annual ORSNZ Conference.

Deng, J.L., 1982. Control Problems of Grey Systems. Systems \& Control Letters, 1 (5), 288-294.

Düzakın E., Demircioğlu M., 2009. Araç Rotalama Problemleri ve Çözüm Yöntemleri. Çukurova Üniversitesi İIBF Dergisi, 13(1), 68-87.

Eryavuz M., Gencer C., 2001. Araç Rotalama Problemine Ait Bir Uygulama. Süleyman Demirel Üniversitesi İktisadi ve İdari Bilimler Fakültesi Dergisi, 6(1), 139-155.

Geiger M.J., Sevaux M., On The Use of Reference Points For the Biobjective Inventory Routing Problem, 2011, Udine, Italy, MIC 2011: The IX Metaheuristics International Conference, 1, 1-14.

Geiger M.J., Sevaux M., 2011. The Biobjective Inventory Routing Problem-Problem Solution And Decision Support. Springer Berlin Heidelberg, 365-378. Hamburg, Germany.
Grønhaug R., Christiansen M., Desaulniers G., Desrosiers J., 2010. A Branch And Price Method For A Liquefied Natural Gas Inventory Routing Problem. Transportation Science: INFORMS, 44, 400-415.

Huang S.H., Lin P.C., 2010. A Modified Ant Colony Optimization Algorithm For Multi-Item Inventory Routing Problems With Demand Uncertainty. Transportation Research Part E: Logistics and Transportation Review, 46, 598611.

Huber S., Geiger M.J., Sevaux M., 2015, Simulation of Preference Information In An Interactive Reference Point-Based Method for the Bi-Objective Inventory Routing Problem. Journal of MultiCriteria Decision Analysis, 22, 17-35.

Hvattum L.M., Løkketangen A., 2009a. Using Scenario Trees And Progressive Hedging For Stochastic Inventory Routing Problems. The Journal of Heuristics, 15, 527-557.

Hvattum L.M., Løkketangen A., Laporte G., $2009 \mathrm{~b}$. Scenario Tree Based Heuristics For Stochastic Inventory Routing Problems. INFORMS Journal on Computing, 21, 268-285.

Jaillet P., Bard J.F., Huang L., Dror M., 2002. Delivery Cost Approximations For Inventory Routing Problems in A Rolling Horizon Frame Work. Transportation Science, 36, 292-300.

Kay M., 2015. Matlog: Logistics Engineering Matlab Toolbox, Erişim Tarihi: 10.10.2015, http://www.ise.ncsu.edu/kay/matlog/.

Kesen S. E., 2012. Bütünleşik Üretim Ve Dağıtım Problemleri İçin Yeni Bir Çözüm Yaklaşımı: Matematiksel Modelleme. Selçuk Üniversitesi Mühendislik-Mimarlık Fakültesi Dergisi, 27(3), 99110.

Kleywegt A.J., Nori V.S., Savelsbergh M.WP., 2002. The Stochastic Inventory Routing Problem with Direct Deliveries. Transportation Science: INFORMS 36, 94-118.

Kleywegt A.J., Nori V.S., Savelsbergh M.W.P., 2004. Dynamic Programming Approximations For a Stochastic Inventory Routing Problem. Transportation Science: INFORMS, 38, 42-70.

Kleywegt A.J., Vijay S.N., Savelsbergh M.W.P., 1998. A Computational Approach For The Inventory Routing Problem. Proc. Triennial Sympos. Transportation Anal.(Tristan III), San Juan, Puerto Rico.

Kulu M.C., 2006. Tedarik Zinciri Yönetiminde Ulaştırma Modeli Optimizasyonu: Otomotiv Sektöründe Bir Uygulama. İstanbul Teknik Üniversitesi, Fen Bilimleri Enstitüsü, Yüksek Lisans Tezi, 75, İstanbul.

Lei L., Liu S., Ruszczynski A., Park S., 2006. On The Integrated Production, Inventory and Distribution Routing Problem. IIE Transactions, 38, 955-970.

Lefever W., Hadj-Hamou K., \& Aghezzaf E. H., 2016. An Adjusted Branch-And-Bound Algorithm For Solving Cyclical Long-Term Inventory Routing Problems. 17ème Congrès Annuel de la Société 
Française de Recherche Opérationnelle et d'Aide à la Décision, Abstracts. Presented at the 17ème Congrès Annuel de la Société Française de Recherche Opérationnelle et d'Aide à la Décision (ROADEF 2016).

Li J., Chen H., Chu F., 2010. Performance Evaluation of Distribution Strategies for The Inventory Routing Problem. The European Journal of Operational Research, 202, 412-419.

Liu S., Lin Y., 2006. Grey Information: Theory and Practical Applications. Springer-Verlag London, 508, London.

Liu S., and Lin Y., 2010. Grey Systems: Theory and Applications. Springer-Verlag Berlin Heidelberg, 379, Berlin.

Michel S., Vanderbeck F., 2012. A Column Generation Based Tactical Planning Method For Inventory Routing. Operations Research: INFORMS , 60, 382397.

Minkoff A.S., 1993. A Markov Decision Model And Decomposition Heuristic For Dynamic Vehicle Dispatching. Operations Research: INFORMS, 41, 77-90.

Moin N.H., Salhi S., Aziz N.A.B., 2011. An Efficient Hybrid Genetic Aalgorithm For the Multi-Product Multiperiod Inventory Routing Problem. The International Journal of Production Economics, 133, 334-343.

Moin N.H., Halim H.Z.A., 2014. Artificial Bee Colony For Inventory Routing Problem With Backordering. International Conference on Inventories, 18-22 Aug 2014, Budapest, Hungary.

Rahim M., Zhong Y., Aghezzaf E.H., Aouamc T., 2014. Modelling and Solving The Multiperiod Inventory Routing Problem with Stochastic Stationary Demand Rates. International Journal of Production Research, 52(14), 4351-4363.

Sadok A., Teghem J., Chabchoub H., 2010. A Hybrid Grouping Genetic Algorithm for the Inventory Routing Problem with Multi-Tours of the Vehicle. International Journal of Combinatorial Optimization Problems and Informatics, 1(2), 4261.

Savelsbergh M., Song J.H., 2008. An Optimization Algorithm for The Inventory Routing Problem with Continuous Moves. Computers \& Operations Research, 35, 2266-2282.

Savelsbergh M., Song J.H., 2007. Inventory Routing with Continuous Moves. Computers \& Operations Research, 34, 1744-1763.

Schönberger J., 2016. Multi-Period Vehicle Routing with Limited Period Load. IFAC Papers OnLine Journal, 49(2), 24-29.

Shukla N., Tiwari M.K., Ceglarek D., 2013. Genetic Algorithms Based Algorithm Portfolio For Inventory Routing Problem With Stochastic Demand. International Journal of Production Research, 51, 118-137.

Solyalı O., Süral H., 2012. The One Warehouse Multi Retailer Problem: Reformulation, Classification,
And Computational Results. Annals of Operations Research, 196, 517-541.

Song J.H., Furman K.C., 2013. A Maritime Inventory Routing Problem: Practical Approach. Computers \& Operations Research, 40, 657-665.

Şişman B., 2012. Talebin Belirsiz Olduğu Tedarik Zinciri Tasarımında Bulanık Eniyileme Yaklaşımı. Uluslararası Yönetim İktisat ve İşletme Dergisi, 8(17), 27-44.

Trudeau P, Dror M., 1992. Stochastic inventory routing: Route design with stock outs and route failures. Transportation Science: INFORMS, 26, 171-184.

Zhao Q. H., Wang S. Y., Lai K. K., 2007. A Partition Approach To The Inventory Routing Problem. The European Journal of Operational Research, 177, 786-802.

Zied J., Yacine R. , Rim K., 2013. Inventory Routing Problems in A Context of Vendor-Managed Inventory System With Consignment Stock And Transshipment. Production Planning \& Control, 24, 8-9. 